\title{
Prevention of ischemia/reperfusion-induced pulmonary dysfunction after cardiopulmonary bypass with terminal leukocyte-depleted lung reperfusion
}

\author{
Hiroshi Kagawa, MD, Kiyozo Morita, MD, Ryuichi Nagahori, MD, Gen Shinohara, MD, \\ Katsushi Kinouchi, MD, and Kazuhiro Hashimoto, MD
}

\begin{abstract}
Objective: Pulmonary ischemia and reperfusion during routine open heart surgery with cardiopulmonary bypass can lead to pulmonary dysfunction and vasoconstriction, resulting in a high morbidity and mortality. We investigated whether ischemia/reperfusion-induced pulmonary dysfunction after full-flow cardiopulmonary bypass could be prevented by the infusion of leukocyte-depleted hypoxemic blood during the early phase of reperfusion (terminal leukocyte-depleted lung reperfusion) and whether the benefits of this method were nullified by using hyperoxemic blood for reperfusion.
\end{abstract}

\begin{abstract}
Methods: Twenty-one neonatal piglets underwent 180 minutes of full-flow cardiopulmonary bypass with pulmonary artery occlusion, followed by reperfusion. The piglets were divided into 3 groups of 7 animals. In group I, uncontrolled reperfusion was achieved by unclamping the pulmonary artery. In contrast, pulmonary reperfusion was done with leukocyte-depleted hyperoxemic blood in group II or with leukocyte-depleted hypoxemic blood in group III for 15 minutes at a flow rate of $10 \mathrm{~mL} / \mathrm{min} / \mathrm{kg}$ before pulmonary artery unclamping. Then the animals were monitored for 120 minutes to evaluate post-cardiopulmonary bypass pulmonary function.
\end{abstract}

Results: Group I developed pulmonary dysfunction that was characterized by an increased alveolar-arterial oxygen difference (204 $\pm 57.7 \mathrm{~mm} \mathrm{Hg}$ ), pulmonary vasoconstriction, and decreased static lung compliance. Terminal leukocyte-depleted lung reperfusion attenuated post-cardiopulmonary bypass pulmonary dysfunction and vasoconstriction when hypoxemic blood was used for reperfusion (alveolar-arterial oxygen difference, $162 \pm 61.0 \mathrm{~mm} \mathrm{Hg}$ ). In contrast, no benefit of terminal leukocyte-depleted lung reperfusion was detected after reperfusion with hyperoxemic blood (alveolar-arterial oxygen difference, $207 \pm 60.8 \mathrm{~mm} \mathrm{Hg}$ ).

Conclusion: Reperfusion with leukocyte-depleted hypoxemic blood has a protective effect against ischemia/ reperfusion-induced pulmonary dysfunction by reducing endothelial damage, cytokine release, and leukocyte activation. (J Thorac Cardiovasc Surg 2010;139:174-80)

Pulmonary dysfunction after cardiac surgery that involves cardiopulmonary bypass $(\mathrm{CPB})$ still remains a major problem, resulting in poor alveolar oxygenation and increased pulmonary vascular resistance $(\mathrm{Rp})$ that requires prolonged artificial ventilation and contributes to a high morbidity and mortality. ${ }^{1,2}$ With respect to the pathogenesis of post-CPB pulmonary dysfunction, CPB per se is known to cause many changes by triggering the systemic inflammatory response syndrome (SIRS). ${ }^{2-5}$ We previously reported on the mechanism of these undesirable changes of lung function after CPB in the Journal, with the major causes being activation of blood components and release of vasoactive substances. ${ }^{6}$ It has been reported that infants and children

From the Department of Cardiac Surgery, The Jikei University School of Medicine, Tokyo, Japan.

Received for publication April 16, 2009; revisions received July 14, 2009; accepted for publication Aug 9, 2009; available ahead of print Nov 18, 2009.

Address for reprints: Hiroshi Kagawa, MD, Department of Cardiac Surgery, The Jikei University School of Medicine, 3-25-8 Nishi-shinbashi, Minato-ku, Tokyo, 1058461, Japan (E-mail: hkagawa@jikei.ac.jp).

$0022-5223 / \$ 36.00$

Copyright (c) 2010 by The American Association for Thoracic Surgery doi: $10.1016 /$ j.jtcvs.2009.08.036 have a more severe inflammatory response to CPB than adults. ${ }^{2}$ In the current era of advanced CPB technology, including development of the membrane oxygenator, surface coating methods, and downsizing of the pump circuit to allow priming without the need for donor blood, the extent of SIRS due to CPB itself may have been minimized, but pulmonary ischemia/reperfusion injury inherent to routine open heart surgery remains a major cause of pulmonary dysfunction and pulmonary vasoconstriction. ${ }^{6,7}$ Although both the heart and the lungs are exposed to ischemia/reperfusion injury during cardiac surgery, protection against such injury is only provided for the heart, and there is no established therapeutic modality for prevention of postoperative pulmonary dysfunction that can be routinely applied. Therefore, in the setting of prolonged total CPB that is used to repair complex cardiac malformations, especially in neonates, a reliable and effective method for prevention of pulmonary ischemia/ reperfusion injury is greatly needed.

Pulmonary dysfunction after CPB is thought to largely occur during the early reperfusion period rather than during ischemia, and this pulmonary ischemia/reperfusion injury is thought to be mainly caused by activated leukocytes during 


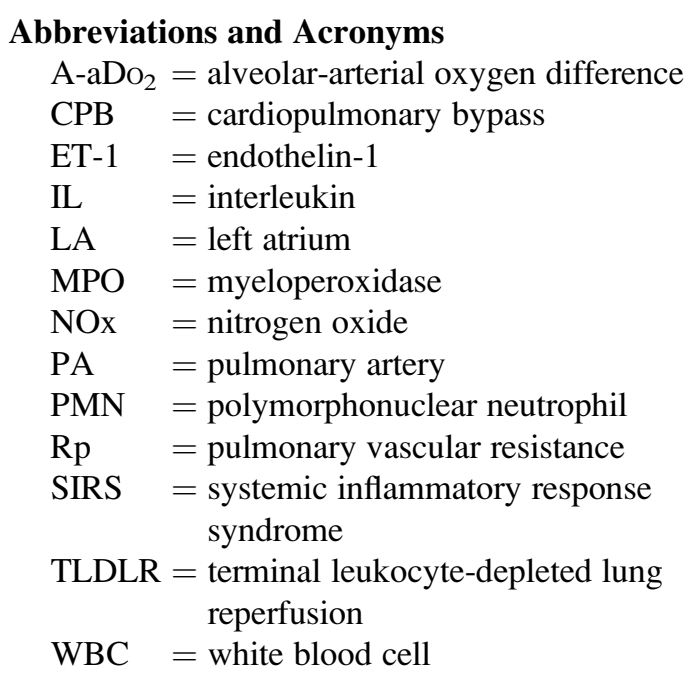

the early phase of pulmonary reperfusion. ${ }^{8,9}$ This implies that successful management of ischemia/reperfusion-induced pulmonary dysfunction may be achieved by controlling lung reperfusion just at the onset of re-flow. By accepting the theory that activated leukocytes and free radicals cause ischemia/ reperfusion-induced pulmonary dysfunction, ${ }^{7}$ we tested the following hypotheses in a neonatal piglet model of prolonged lung ischemia with full-flow CPB: (1) ischemia/reperfusioninduced pulmonary dysfunction after CPB can be prevented by terminal leukocyte-depleted lung reperfusion (TLDLR, ie, initial pulmonary reperfusion with leukocyte-depleted hypoxemic blood), and (2) the protective effect of TLDLR against ischemia/reperfusion-induced pulmonary dysfunction would be nullified by reperfusion with hyperoxemic blood instead of hypoxemic blood.

\section{MATERIALS AND METHODS}

\section{Animals and Cardiopulmonary Bypass Preparation}

Twenty-one neonatal piglets (Large White Landrace Duroc) weighing $13.2 \pm 1.9 \mathrm{~kg}$ (mean \pm standard deviation) were used for this study. Use of these animals and the study protocol were approved by the animal welfare committee of The Jikei University School of Medicine. All animals received humane care in compliance with the "Principles of Laboratory Animal Care" formulated by the National Society for Medical Research and the "Guide for the Care and Use of Laboratory Animals" prepared by the National Academy of Science and published by the National Institutes of Health (publication 96-03, revised 1996).

Animals were sedated with intravenous thiopental sodium $(10 \mathrm{mg} / \mathrm{kg})$, and endotracheal intubation was performed. Mechanical ventilation was performed at a rate of 20 breaths/min and a tidal volume of $15 \mathrm{~mL} / \mathrm{kg}$ with an ACE-300 (ACOMA, Tokyo, Japan). General anesthesia was maintained with nitrous oxide $(1 \mathrm{~L} / \mathrm{min})$, oxygen $(1 \mathrm{~L} / \mathrm{min})$, and sevoflurane $(2.5 \%)$.

With the piglet in the supine position, the femoral artery was cannulated for arterial access and the central venous line was advanced through the femoral vein into the inferior vena cava. Arterial blood samples were drawn periodically and analyzed by an i-STAT 300F (Fuso Pharmaceutical Industries, Ltd, Osaka, Japan). Midline sternotomy and pericardiotomy were per- formed. After administration of heparin $(300 \mathrm{U} / \mathrm{kg}$ ), the arterial cannula was placed in the right common carotid artery (Fem-Flex II cannula, Edwards Lifesciences, Irvine, Calif) and the venous cannula was placed in the right atrium (DLP angled metal tip [Pacifico] cannula, Medtronic, Inc, Minneapolis, MN). The left atrium (LA) and pulmonary artery (PA) were also cannulated to monitor the LA and PA pressures. An ultrasonic blood flow meter (T201, Transonic Systems Inc, Ithaca, NY) was placed around the main PA to measure PA flow. The extracorporeal circuit consisted of a roller pump (Terumo Corp, Tokyo, Japan) and a membrane oxygenator (Capiox RX05, Terumo Corp). This circuit was primed with $120 \mathrm{~mL}$ of Ringer's acetate solution, $40 \mathrm{~mL}$ of $20 \%$ albumin, $30 \mathrm{~mL}$ of $20 \%$ mannitol, and $20 \mathrm{~mL}$ of $7 \%$ sodium bicarbonate, eliminating the need for donor blood priming. Blood transfusion was not done because it has been reported that transfusion can cause pulmonary dysfunction. ${ }^{10}$

\section{Study Protocol and Groups}

All piglets were subjected to 180 minutes of full-flow CPB with clamping of the main PA (to create pulmonary ischemia), starting from 5 minutes after the onset of normothermic CPB at a flow rate of $100 \mathrm{~mL} / \mathrm{min} / \mathrm{kg}$, and followed by 25 minutes of pulmonary reperfusion on CPB (Figure 1). We observed the piglets for 120 minutes after the termination of CPB. During full-flow CPB with PA clamping, venting of the PA and right ventricle was performed to ensure pulmonary ischemia, eliminate the influence of collateral flow into the pulmonary circulation from systemic arteries, and avoid right ventricular overdistension. We could remove the effect of bronchial blood flow by these ventings. Hematocrit was kept at $22 \%$ to $25 \%$ during perfusion without blood transfusion by the application of hemofiltration. During $\mathrm{CPB}$, the arterial partial pressure of oxygen was maintained between 200 and $300 \mathrm{~mm} \mathrm{Hg}$ and pulmonary ventilation was stopped during full-flow $\mathrm{CPB}$. The heart was beating during $\mathrm{CPB}$.

The piglets were divided into 3 groups by the mode of pulmonary reperfusion. In group I, the clamp on the main PA was simply removed to allow uncontrolled pulmonary reperfusion for 25 minutes on CPB. This reperfusion was uncontrolled systemic venous reperfusion at the flow of $10 \mathrm{~mL} / \mathrm{min} / \mathrm{kg}$. In group II, 180 minutes of full-flow CPB with PA occlusion was followed by 15 minutes of TLDLR with leukocyte-depleted hyperoxemic blood from the $\mathrm{CPB}$ circuit at a flow rate of $10 \mathrm{~mL} / \mathrm{min} / \mathrm{kg}$. This oxygenated blood was removed from the arterial line of the $\mathrm{CPB}$, passed through a leukocyte-depleting filter (Pall LeukoGuard BC2 Cardioplegia Filter, Pall Corporation, East Hills, NY), and administered through a cannula that had been inserted into the main PA distal to the clamping site. In group II, the partial pressure of oxygen in the pulmonary reperfusate was $257 \pm 29.3 \mathrm{~mm} \mathrm{Hg}$. After 15 minutes of selective pulmonary reperfusion, the main PA was declamped, followed by another 10 minutes of uncontrolled reperfusion on CPB and 120 minutes of observation after the termination of CPB. In group III, after 180 minutes of full-flow CPB with PA occlusion, 15 minutes of TLDLR was also performed with leukocyte-depleted hypoxemic blood from the venous reservoir of the $\mathrm{CPB}$ circuit instead of hyperoxemic blood. In group III, the partial pressure of oxygen in the pulmonary reperfusate was $50.0 \pm 12.6 \mathrm{~mm} \mathrm{Hg}$.

\section{Assessment of Pulmonary Function}

We evaluated various parameters of lung function, including the alveolar-arterial oxygen difference $\left(\mathrm{A}-\mathrm{aDo}_{2}\right)$, static lung compliance, and $\mathrm{Rp}$. Measurements were obtained before CPB (baseline) and 15 minutes, 1 hour, and 2 hours after the termination of $\mathrm{CPB}$.

$\mathrm{A}-\mathrm{aDo}_{2}$ was calculated by using the following formula:

$$
\mathrm{A}-\mathrm{aDo}_{2}(\mathrm{~mm} \mathrm{Hg})=\mathrm{FiO}_{2} \times 713-\mathrm{PaCO}_{2} / 0.8-\mathrm{PaO}_{2}
$$

where $\mathrm{FIO}_{2}$ is the inspired fraction of oxygen, $\mathrm{PaCO}_{2}$ is the arterial partial pressure of carbon dioxide, and $\mathrm{PaO}_{2}$ is the arterial partial pressure of oxygen.

Static lung compliance was determined from duplicate expirations using a volume-limited ventilator. The expiratory plateau pressure was recorded for 2 breaths each at 4 different tidal volumes without positive end- 

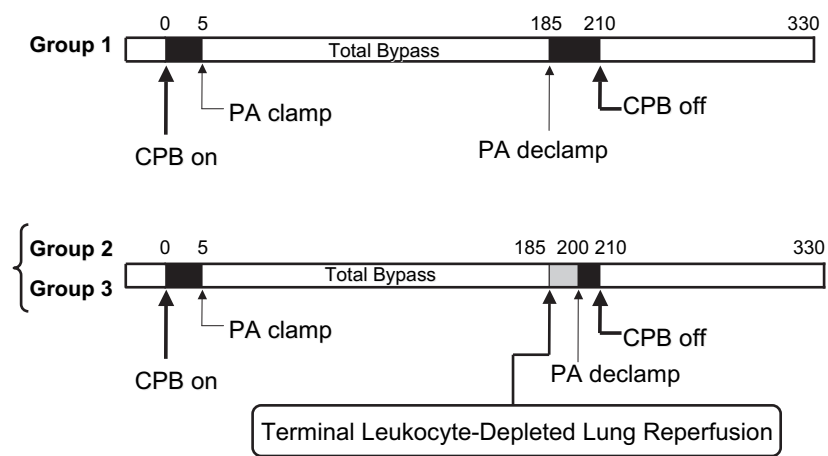

FIGURE 1. In group I, the clamp on the main PA was removed after 180minutes of total CPB, followed by monitoring for another 120 minutes to evaluate pulmonary function. In groups II and III, modified reperfusion was done for 15 minutes before removing the main PA clamp. $C P B$, Cardiopulmonary bypass; $P A$, pulmonary artery.

expiratory pressure. Static lung compliance was calculated as the change of volume/change of pressure $\left(\mathrm{mL} / \mathrm{cm} \mathrm{H}_{2} \mathrm{O}\right)$.

PA and LA pressures were monitored during the experiment, and PA flow was measured by the ultrasonic blood flow meter. These data were used to calculate $\mathrm{Rp}$ by the following formula:

$\operatorname{Rp}\left(\right.$ dynes $\left.\times \sec ^{-1} \times \mathrm{cm}^{-5}\right)=($ PA pressure - LA pressure $) /$ PA flow $\cdot 80$

\section{Measurement of Plasma Parameters}

Pulmonary venous blood samples were obtained at the following 5 times: before CPB (baseline), just before the termination of CPB, and 15 minutes, 1 hour, and 2 hours after the termination of CPB. Then the plasma concentrations of nitrogen oxide (NOx) and endothelin-1 (ET-1) were measured.

\section{Measurement of Lung Tissue Parameters \\ Wedge biopsy of the lung was done at the same 5 sampling points to pul- monary venous blood samples. Lung tissue was homogenized to measure myeloperoxidase (MPO) activity and interleukin (IL)-6 level. The remain- ing specimen was weighed and dried to a constant weight by heating at $80^{\circ} \mathrm{C}$ for 24 hours, after which the dry weight was measured. Then the tissue water content was measured and expressed as a percentage using the follow- ing formula:}

Lung tissue water content $(\%)=(1-$ dry weight $/$ wet weight $) \times 100$

We confirmed in the control group that the volume of specimen was too small to influence the lung function.

\section{Statistical Analysis}

Statistical analysis was performed with STATA software (College Station, TX). Data are expressed as the mean \pm standard deviation. Repeated-measures analysis of variance, followed by the Bonferroni multiple comparison test, was used to analyze group effects and time effects.

\section{RESULTS}

\section{White Blood Cell Counts}

Before CPB, white blood cell (WBC) counts were similar in the 3 groups (Figure 2). After pulmonary reperfusion, there was no decrease of WBC in group I, but, WBC decreased by $50 \%$ in group II and by $40 \%$ in

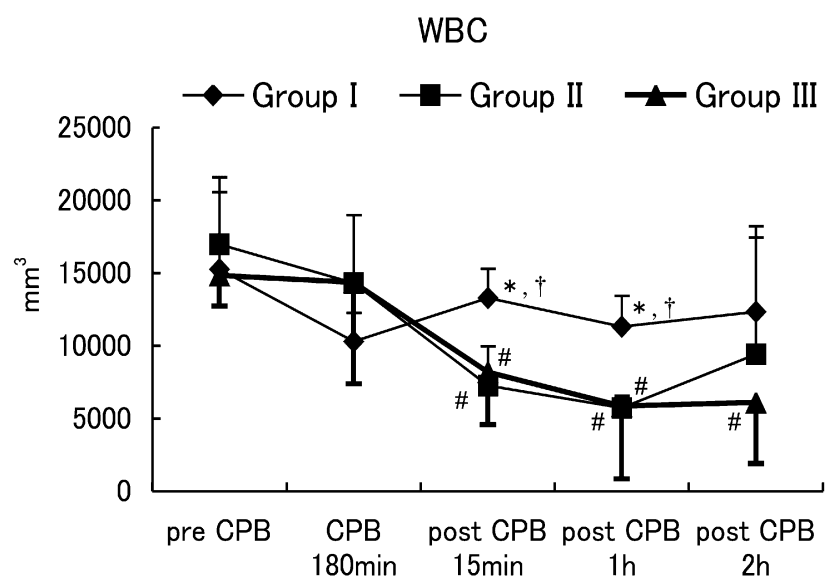

FIGURE 2. Before CPB, WBC counts were similar in the 3 groups. After pulmonary reperfusion, there was no decrease of WBC in group I, but WBC decreased by $50 \%$ in group II and by $40 \%$ in group III ( $* P<.05$ vs group II; $\dagger P<.05$ vs group III; \#P<.05 vs pre-CPB). WBC, White blood cell; $C P B$, cardiopulmonary bypass.

group III $(P<.05)$. WBC counts were significantly decreased by the leukocyte-depleting filter. The efficacy of leukocyte depletion was not dependent on oxygen tension, and, WBC counts in the reperfusion solution were also decreased by $90 \%$.

\section{Pulmonary Function}

Alveolar-arterial oxygen difference. Before $\mathrm{CPB}$, there was no significant difference of $\mathrm{A}-\mathrm{aDo}_{2}$ among the 3 groups (Figure 3,A). $\mathrm{A}-\mathrm{aDo}_{2}$ deteriorated significantly after total $\mathrm{CPB}$ in group I and showed a significant increase compared with the pre-CPB value throughout the observation period (pre-CPB, $130 \pm 28.4 \mathrm{~mm} \mathrm{Hg}$; post-CPB 2 hours, $204 \pm$ $57.7 \mathrm{~mm} \mathrm{Hg} ; P<.05)$. In contrast, $\mathrm{A}-\mathrm{aDo}_{2}$ did not increase after CPB and was lower in group III than in the other 2 groups (pre-CPB, $130 \pm 65.9 \mathrm{~mm} \mathrm{Hg}$; post-CPB 2 hours, $162 \pm 61.0 \mathrm{~mm} \mathrm{Hg}$ ). The results showing that $\mathrm{A}-\mathrm{aDo}_{2}$ in group II was comparable to that of group I suggested that perfusion with hyperoxemic blood instead of hypoxemic blood nullified the benefits of TLDLR.

Lung compliance. There was no significant difference of lung compliance among the 3 groups before $\mathrm{CPB}$, but compliance was significantly reduced in group I after CPB compared with the baseline value and stayed low throughout the observation period (Figure 3, B). In contrast, impairment of lung compliance was significantly less marked in group III compared with group I, whereas the improvement of lung compliance was inconsistent in group II $(P<.05$ between group I and III).

Pulmonary vascular resistance. Rp increased significantly after CPB in group I, although there was no difference of Rp among the groups before CPB (Figure 3,C). This indicates that ischemia/reperfusion-induced pulmonary vasoconstriction occurred after total CPB. The increase of 


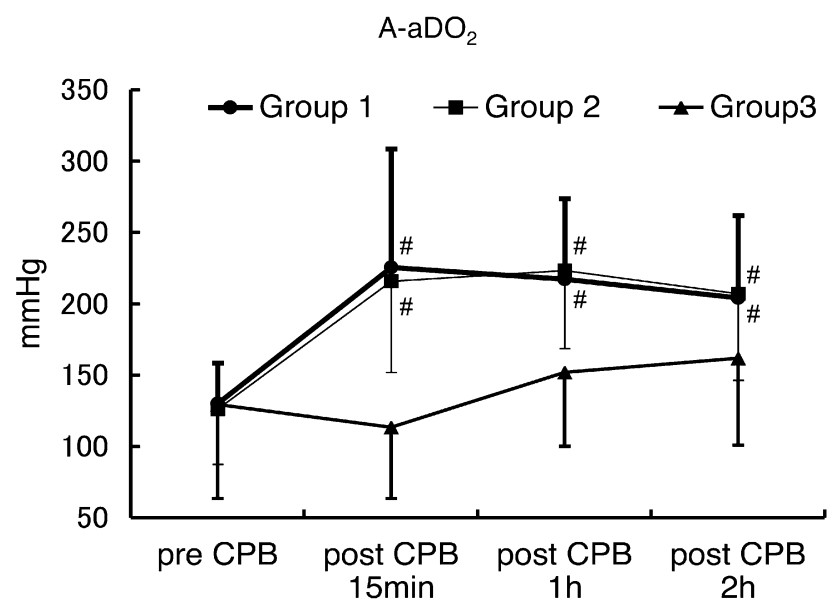

A

Lung Compliance

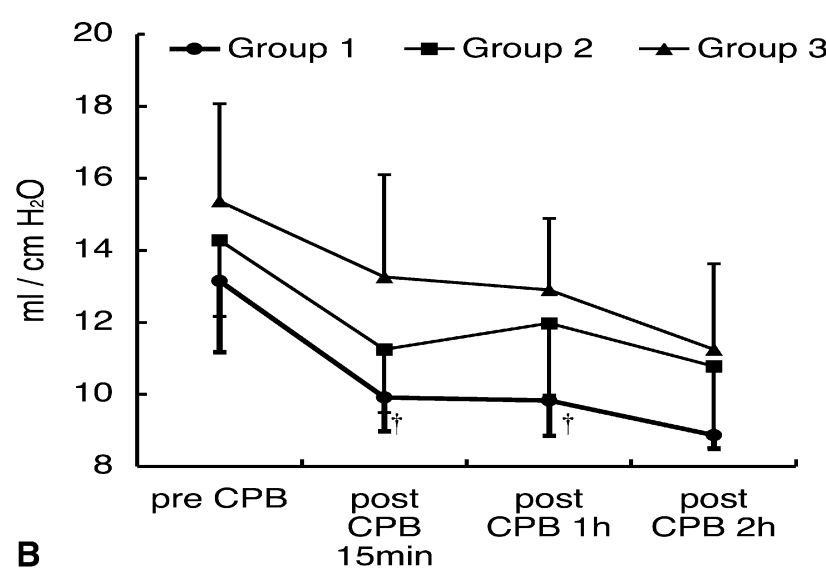

Rp

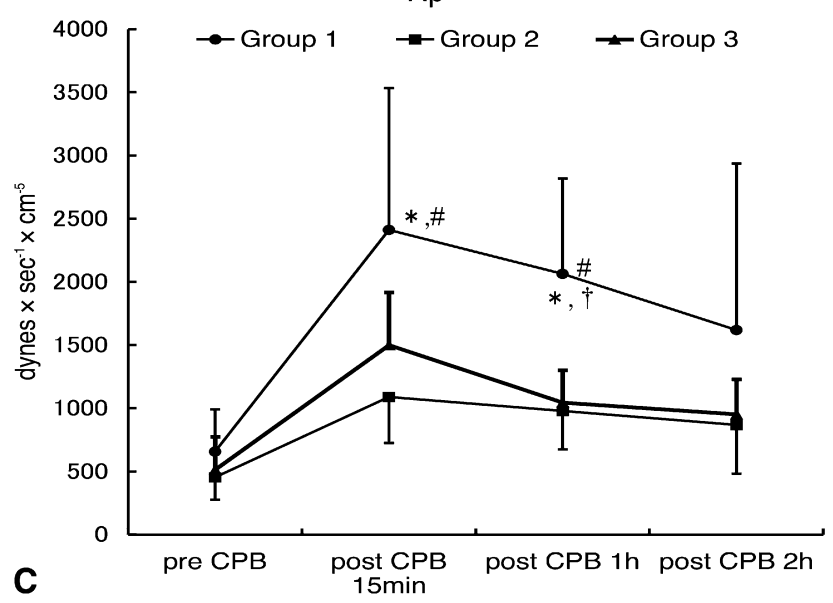

FIGURE 3. $\mathrm{A}, \mathrm{A}-\mathrm{aDo}_{2}$ was measured before $\mathrm{CPB}$ and 15 minutes, 1 hour, and 2 hours after CPB $(\# P<.05$ vs pre-CPB). B, Lung compliance was measured before $\mathrm{CPB}$ and 15 minutes, 1 hour, and 2 hours after $\mathrm{CPB}(\dagger P$ $<.05$ vs group III). C, Rp was measured before $\mathrm{CPB}$ and 15 minutes, 1 hour, and 2 hours after CPB $(* P<.05$ vs group II, $\dagger P<.05$ vs group III, $\# P<.05$ vs pre-CPB). $A-a D O_{2}$, Alveolar-arterial oxygen difference; $C P B$, cardiopulmonary bypass.
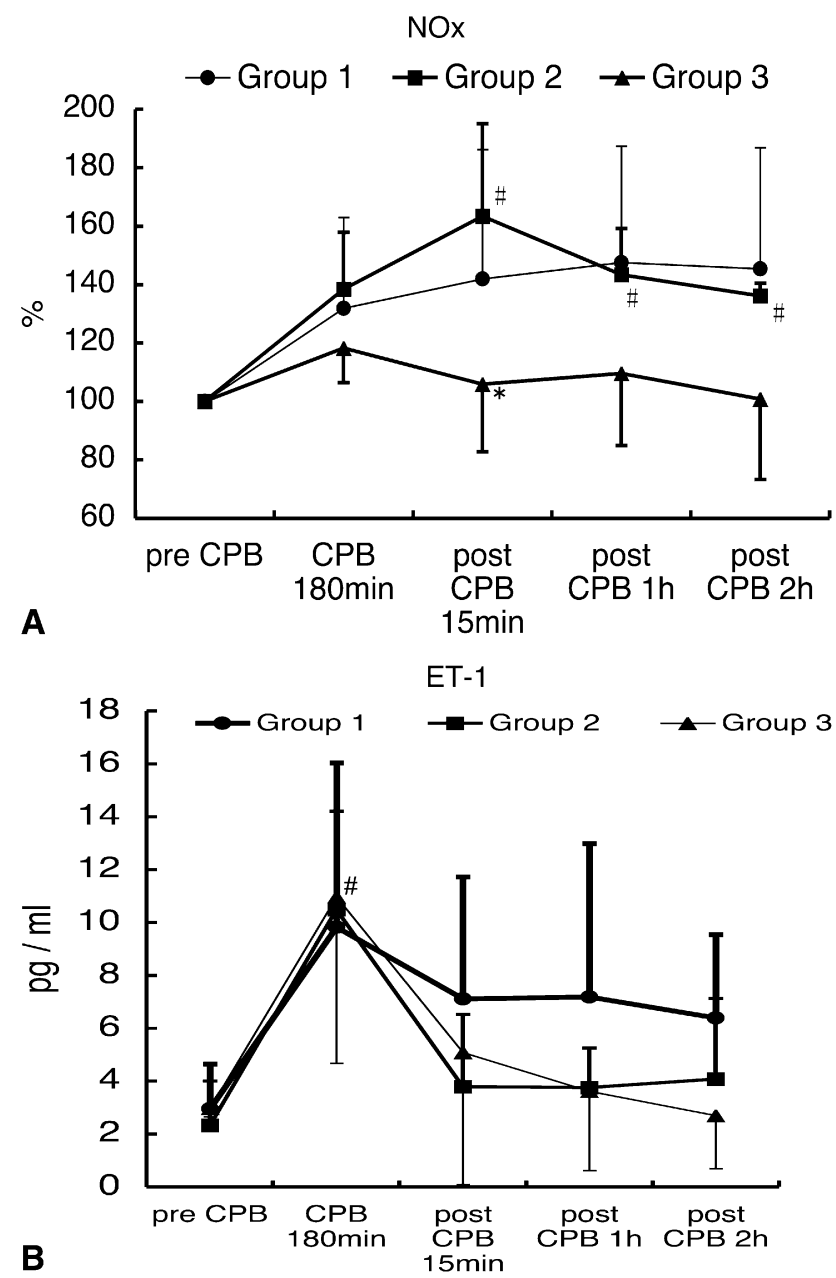

FIGURE 4. Pulmonary venous blood samples were obtained from the LA at the following 5 times: before $\mathrm{CPB}$ (baseline), just before the termination of $\mathrm{CPB}$, and 15 minutes, 1 hour, and 2 hours after the termination of $\mathrm{CPB}$. NOx (A) and ET-1 (B) $(* P<.05$ vs group II, \#P<.05 vs pre-CPB). NOx, Nitrogen oxide; $C P B$, cardiopulmonary bypass.

Rp after CPB was significantly smaller in groups II and III $(P<.05)$.

\section{Pulmonary Venous Blood Parameters}

Plasma nitrogen oxide concentration. There were no differences in the plasma NOx level among the 3 groups before CPB $(28.8 \pm 17.1$ in group I, $26.8 \pm 9.77$ in group II, $27.4 \pm$ $3.54 \mu \mathrm{mol} / \mathrm{L}$ in group III) (Figure $4, A$ ). NOx gradually increased after the start of pulmonary reperfusion in groups I and II, whereas NOx was unaltered in group III and lower than in the other 2 groups.

Plasma endothelin-1 concentration. There were no differences in ET-1 levels among the 3 groups before $\mathrm{CPB}$ and just before reperfusion (Figure 4, $B$ ). In group I, ET-1 remained higher than in the other groups after termination of $\mathrm{CPB}$, whereas it returned to the pre-CPB range in groups II and III. 


\section{Lung Tissue Parameters}

Myeloperoxidase activity. Until the end of CPB, there was no increase of MPO activity or differences among the 3 groups (Figure 5, A). In groups I and II, MPO activity showed a considerable increase after the termination of $\mathrm{CPB}$, whereas it was slightly lower in group III than in the other groups $(P<.05$ between group II and III).

Interleukin-6 level. In group I, IL-6 showed a sudden increase after the onset of pulmonary reperfusion. This increase of IL-6 after reperfusion was less marked in groups II and III $(P<.05)$ (Figure 5, B).

Water content. No significant change of the water content was detected during $\mathrm{CPB}$ in the 3 groups. Although the water content increased during lung reperfusion in all groups, the increase was smaller in groups II and III compared with group I (Figure 5, C).

\section{DISCUSSION}

The present study confirmed that pulmonary dysfunction, characterized by reduced alveolar oxygenation and lung compliance associated with pulmonary vasoconstriction, occurred after full-flow CPB in a neonatal piglet model of prolonged lung ischemia, which was used to simulate pediatric open heart surgery. We demonstrated that a) this ischemia/ reperfusion-induced pulmonary dysfunction can be prevented by terminal leukocyte-depleted lung reperfusion (TLDLR), which involves initial pulmonary reperfusion with leukocyte-depleted blood, and that b) the beneficial effect of TLDLR on ischemia/reperfusion-induced pulmonary dysfunction was lost if hyperoxemic blood was used for reperfusion instead of hypoxemic blood. Given the concern about the detrimental effects of hyperoxemic reperfusion, we first confirmed the crucial importance of the oxygen tension during pulmonary reperfusion. The method examined may be useful as a rescue strategy in the circumstances in which pulmonary ischemia is unexpectedly prolonged, particularly in patients lacking sufficient bronchial or systemic collateral flow into the pulmonary vasculature to avoid lung ischemia during CPB. It is easy to perform this procedure whenever required during the final minutes of pulmonary ischemia. In clinical lung transplantation, Schnickel and colleagues ${ }^{11}$ used a similar method of reperfusion with leukocyte-depleted solution for 10 minutes. The results that we obtained in this study were also similar to theirs, indicating that the present model has a pathophysiology closely resembling that of clinical CPB.

Pulmonary dysfunction is a well-known adverse effect of CPB. CPB alters many factors simultaneously ${ }^{2-6}$ and causes SIRS, including complement-mediated neutrophil activation, ${ }^{5,6}$ production of oxygen free radicals, ${ }^{3}$ and generation of vasoactive mediators. ${ }^{4}$ Post-CPB lung complications ${ }^{2,4,6}$ cover a wide spectrum from gas-exchange abnormalities to hemodynamic derangement. Acute pulmonary dysfunction

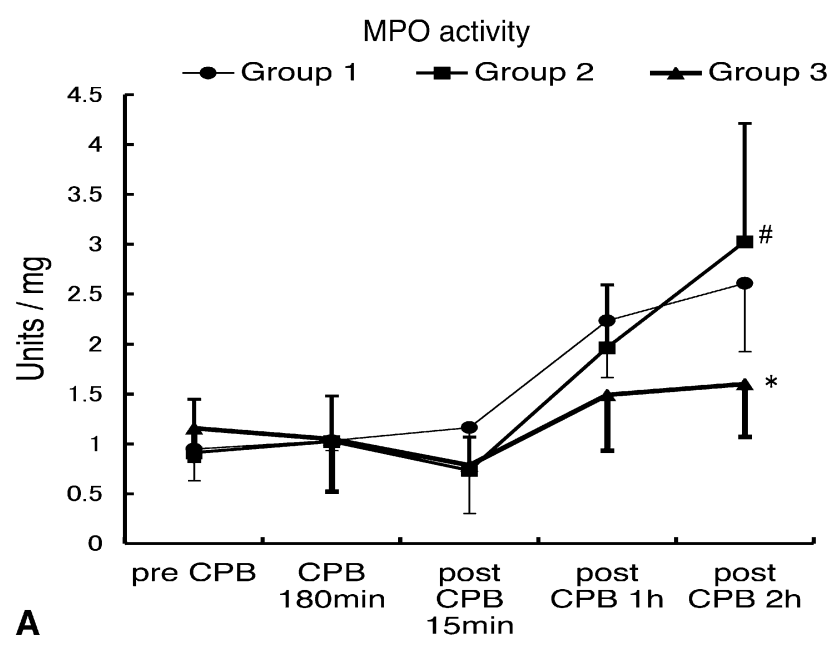

IL-6
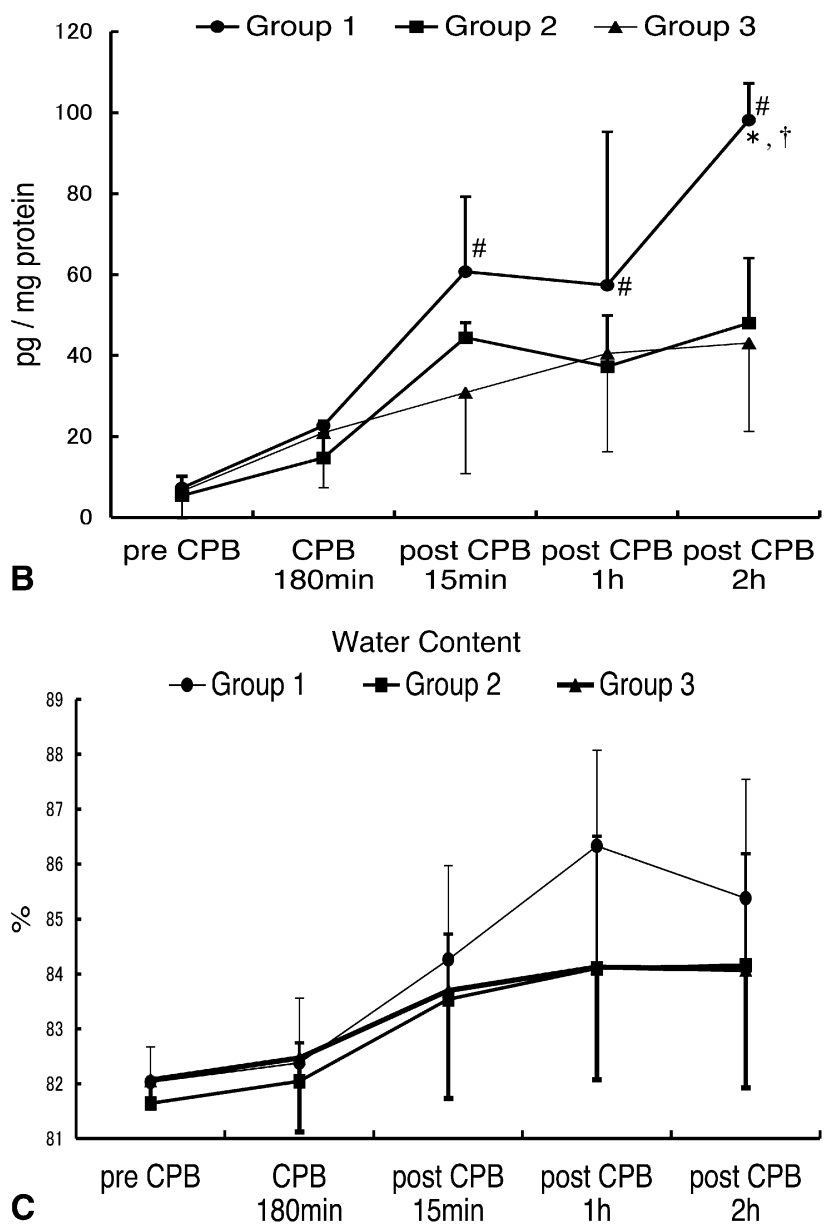

FIGURE 5. Wedge biopsy of the lung was done to measure MPO activity (A), IL-6 (B), and water content (C) in lung tissue ( $* P<.05$ vs group II, $\dagger P$ $<.05$ vs group III, \# $P<.05$ vs pre-CPB). $M P O$, Myeloperoxidase; $C P B$, cardiopulmonary bypass.

was reported to occur after cardiac surgery in $0.4 \%$ to $3 \%$ of patients undergoing $\mathrm{CPB}$, and the associated mortality rate is high $(15 \%-70 \%){ }^{12,13}$ However, the latest advances 
in CPB systems and circuits have markedly reduced the contribution of $\mathrm{CPB}$ per se to the pathogenesis of postoperative pulmonary dysfunction, as indicated by a recent report of no difference in the extent of SIRS and lung dysfunction between off-pump and on-pump coronary bypass surgery. ${ }^{14} \mathrm{We}$ also confirmed in our pilot study (with a similar design to the present protocol) that there was little pulmonary dysfunction after partial CPB when lung perfusion was maintained at 10 $\mathrm{mL} / \mathrm{min} / \mathrm{kg}$ and a membrane oxygenator was used without donor blood priming (unpublished data).

Another potential major determinant of post-CPB pulmonary dysfunction is pulmonary ischemia/reperfusion injury. ${ }^{15}$ Unlike other organs in the human body, the lungs possess 2 blood supply networks with extensive anastomotic connections. Nevertheless, the fact that CPB reduces perfusion of the bronchial vessels raises concern about pulmonary ischemia during total CPB. Careful management of the early reperfusion period is important. This was the rationale for our concept of early leukocyte-depleted pulmonary reperfusion. For the prevention or treatment of SIRS and acute pulmonary dysfunction after CPB, several distinct strategies have been used to protect against injury related to polymorphonuclear neutrophils (PMNs), including pharmacologic intervention $^{16}$ and removal of WBCs from blood in the CPB circuit by filtration. ${ }^{17}$ In most of the previous studies, however, the leukocyte-depleting filter was connected to the arterial line of the CPB circuit and was intended to reduce the total number of circulating PMNs for amelioration of SIRS. In our study, however, the leukocyte-depleting filter was only placed in the pulmonary arterial line, and targeted leukocyte depletion was more specific and efficient for preventing reperfusion injury. With respect to the optimal method of leukocyte-depleted reperfusion, there have been no reports about the influence of the duration of leukocyte depletion. In our pilot study, leukocyte depletion was performed for 5,15 , and 30 minutes in the same ischemia/reperfusion model. There was a negligible effect of depletion for $5 \mathrm{~min}-$ utes, but comparable effects of depletion for 15 and $30 \mathrm{~min}$ utes. This suggests that leukocyte depletion for 15 minutes may be adequate if the ischemic period is approximately 3 hours. We also considered the influence of the flow rate during pulmonary reperfusion. We hypothesized that low-flow reperfusion rather than rapid reperfusion might ameliorate pulmonary dysfunction after CPB. The flow rate used by Halldorsson and colleagues ${ }^{18}$ in their experiments on ischemia/reperfusion injury in pigs was approximately $20 \mathrm{~mL} /$ $\mathrm{min} / \mathrm{kg}$, so we performed PA reperfusion at $10 \mathrm{~mL} / \mathrm{min} / \mathrm{kg}$, which was approximately half of that rate. They also reported a similar benefit of leukocyte-depleted lung reperfusion in a regional lung ischemia model without CPB. ${ }^{18}$ In that study, they clamped the right PA and took blood from femoral artery that was passed through a leukocyte-depleting filter before being returned to the right PA. Although their basic concept and method seem to be similar to ours, they demonstrated a benefit of lung reperfusion with hyperoxemic blood, unlike the present study in which we found that the use of hyperoxemic blood was detrimental and nullified the benefit of leukocyte depletion. This suggests that pulmonary dysfunction after CPB may be influenced by the fact that CPB itself causes the onset of SIRS, thus making the lungs more susceptible to oxidative injury during hyperoxemic reperfusion.

Activated PMNs can release a number of proteolytic enzymes and oxidative agents into the systemic circulation and lung tissue. These substances include PMN elastase, ${ }^{8,16}$ oxygen free radicals, and MPO. ${ }^{19}$ MPO is an indicator of the production of reactive oxygen species and an index of neutrophil activation. MPO activity was lower in group III than in groups I and II, which implies that the low oxygen concentration inhibited MPO release by affecting neutrophil function. It has been proposed that an increase of free radicals represents a potential risk factor for pulmonary dysfunction after $\mathrm{CPB} .{ }^{20}$ In fact, hyperoxic $\mathrm{CPB}$ is widely used in cardiac surgery, and there is some concern about whether excessive oxygenation may induce the production of oxygenderived free radicals. It has been suggested that hyperoxic CPB increases oxygen free radical damage to the lungs compared with normoxic CPB. ${ }^{21}$ The present study also demonstrated that hypoxemic blood was superior to hyperoxemic blood as the pulmonary reperfusate in terms of protecting the lungs.

Serum and bronchoalveolar lavage fluid levels of IL-6 are sensitive indicators of the severity of pulmonary dysfunction and are correlated with postoperative morbidity. ${ }^{5,22}$ In this study, we measured the IL-6 level in lung tissue rather than serum because the serum concentration of IL- 6 after CPB is influenced by many factors in addition to pulmonary inflammation, for example, a considerable amount of IL- 6 can be released from organs such as the heart and muscles. This study showed that groups II and III had lower lung tissue IL-6 levels than group I, suggesting that leukocyte depletion is an effective method of decreasing pulmonary inflammation after CPB.

Pulmonary vasoconstriction has been demonstrated after $\mathrm{CPB}$, both experimentally ${ }^{5,23}$ and clinically. ${ }^{4,6,24}$ Some reports have suggested a role of ischemia/reperfusion-induced pulmonary endothelial cell dysfunction, possibly because of local activation of the complement-leukocyte system leading to free radical generation. ${ }^{4-6,23}$ The endothelium has an important role in regulating vascular tone by releasing vasoactive mediators, including endothelin, nitric oxide, prostacyclin, and thromboxanes. It is well known that the pulmonary endothelium is the initial target of extracellular free radical attack, resulting in endothelium-derived vasoconstriction. ${ }^{25}$ By measurement of plasma ET-1 and NOx levels, we confirmed that lung ischemia/reperfusion during total CPB produced pulmonary vasoconstriction that was related to the severity of pulmonary endothelial dysfunction. Leukocyte depletion during reperfusion markedly reduced post-CPB pulmonary vasoconstriction by avoiding the 
accumulation of activated leukocytes that could cause endothelial dysfunction.

\section{CONCLUSIONS}

To our knowledge, this is the first study to evaluate the effect of leukocyte-depleted pulmonary reperfusion in piglets after full-flow CPB with PA occlusion and no donor blood priming. We showed that ischemia/reperfusion-induced pulmonary dysfunction after CPB can be prevented by initial pulmonary reperfusion with leukocyte-depleted hypoxemic blood, which reduces the inflammatory response, endothelial damage, and leukocyte activation. Because of the limitations of this study, including the small number of animals and large variability of measured values, many comparisons did not reach statistical significance and we could not clarify the causes of this type of lung injury or the mechanism underlying the benefits of leukocyte depletion. However, this study provides a rationale for protection of the lungs during $\mathrm{CPB}$ and should promote further research.

\section{References}

1. Kirklin JK, Blackstone EH, Kirklin JW, McKay R, Pacifico AD, Bargeron LJ Jr. Intracardiac surgery in infants under age 3 months: Incremental risk factors for hospital mortality. Am J Cardiol. 1981;48:500-6.

2. Kirklin JK, Westaby S, Blackstone EH, Kirklin JW, Chenoweth DE, Pacifico AD. Complement and the damaging effects of cardiopulmonary bypass. J Thorac Cardiovasc Surg. 1983;86:845-7.

3. Cavarocchi NC, England MD, Schaff HV, Russo P, Orszulak TA, Schnell WA Jr, et al. Oxygen free radical generation during cardiopulmonary bypass: correlation with complement activation. Circulation. 1986;74(Suppl III). III-130-3.

4. Greeley WJ, Bushman GA, Kong DL, Oldham HN, Peterson MB. Effects of cardiopulmonary bypass on eicosanoid metabolism during pediatric cardiovascular surgery. J Thorac Cardiovasc Surg. 1988;95:842-9.

5. Bando K, Pillai R, Cameron DE, Brawn JD, Winkelstein JA, Hutchins GM, et al. Leukocyte depletion ameliorates free radical- mediated lung injury after cardiopulmonary bypass. J Thorac Cardiovasc Surg. 1990;99:873-7.

6. Hashimoto K, Miyamoto H, Suzuki K, Horikoshi S, Matsui M, Arai T, et al. Evidence of organ damage following a cardiopulmonary bypass. The role of elastase and vasoactive mediators. J Thorac Cardiovasc Surg. 1992;104:666-73.

7. $\mathrm{Ng} \mathrm{CSH,} \mathrm{Wan} \mathrm{S,} \mathrm{Arifi} \mathrm{AA,} \mathrm{Yim} \mathrm{APC.} \mathrm{Inflammatory} \mathrm{response} \mathrm{to} \mathrm{pulmonary} \mathrm{is-}$ chemia-reperfusion injury. Surg Today. 2006;36:205-14.

8. Chai PJ, Williamson JA, Lodge AJ, Daggett CW, Scarborough JE, Meliones JN, et al. Effects of ischemia on pulmonary dysfunction after cardiopulmonary bypass. Ann Thorac Surg. 1999;67:731-5.
9. Friedman M, Sellke FW, Wang SY, Weintraub RM, Johnson RG. Parameters of pulmonary injury after total or partial cardiopulmonary bypass. Circulation. 1994; 90:262-8.

10. Spies B. Transfusion of blood products affects outcome in cardiac surgery. Semin Cardiothorac Vasc Anesth. 2004;8:267-81.

11. Schnickel GT, Ross DJ, Beygui R, Shefizadeh A, Laks H, Saggar R, et al. Modified reperfusion in clinical lung transplantation: the results of 100 consecutive cases. J Thorac Cardiovasc Surg. 2006;1:218-23.

12. Okabayashi K, Aoe M, DeMeester SR, Cooper JD, Patterson A. Pentoxifylline reduces lung allograft reperfusion injury. Ann Thorac Surg. 1994;58: 50-6.

13. Messent M, Sullivan K, Keogh BF, Morgan CJ, Evans TW. Adult respiratory distress syndrome following cardiopulmonary bypass: incidence and prediction. Anaesthesia. 1992;47:267-8.

14. Cox CM, Ascione R, Cohen AM, Davies IM, Ryder IG, Angelini GD. Effect of cardiopulmonary bypass on pulmonary gas exchange: a prospective randomized study. Ann Thorac Surg. 2000;69:140-5.

15. Kaul TK, Fields BL, Riggins LS, Wyatt DA, Jonas CR, Nagle D. Adult respiratory distress syndrome following cardiopulmonary bypass: incidence, prophylaxis and management. J Cardiovasc Surg. 1998;39:777-81.

16. Hashimoto K, Nomura K, Nakano M, Sasaki T, Kurosawa H. Pharmacological intervention for organ protection during cardiopulmonary bypass. Heart Vessels. 1993;8:203-10.

17. Tonz M, Mihaljevic T, von Segesser LK, Fehr J, Schmidt ER, Turina MI. Acute lung injury during cardiopulmonary bypass. Are the neutrophils responsible? Chest. 1995;108:1551-6.

18. Halldorsson A, Kronon M, Allen BS, Bolling KS, Wang T, Rahman S, et al. Controlled reperfusion after lung ischemia: implications for improved function after lung transplantation. J Thorac Cardiovasc Surg. 1998;115:415-25.

19. Asimakopoulos G, Smith PL, Ratnatunga CP, Taylor KM. Lung injury and acute respiratory distress syndrome after cardiopulmonary bypass. Ann Thorac Surg. 1999;68:1107-15.

20. Chen YF, Tsai WC, Lin CC, et al. Effect of leukocyte depletion on endothelial cell activation and transendothelial migration of leukocytes during cardiopulmonary bypass. Ann Thorac Surg. 2004;78:634-43.

21. Tanita T, Song C, Kubo H, et al. Superoxide anion mediates pulmonary vascular permeability caused by neutrophils in cardiopulmonary bypass. Surg Today. 1999;29:755-61.

22. Ihnken K, Winkler A, Schlensak C, et al. Normoxic cardiopulmonary bypass reduces oxidative myocardial damage and nitric oxide during cardiac operations in the adult. J Thorac Cardiovasc Surg. 1998;116:327-34.

23. Mashburn JP, Kontos GJ Jr, Hashimoto K, Wilson DM, Schaff HV. The role of neural and vasoactive mediators in the regulation of the pulmonary circulation during cardiopulmonary preservation. J Thoracic Cardiovasc Surg. 1989;98: 434-43.

24. Latson TW, Kirckler TS, Baumgartner WA. Pulmonary hypertension and noncardiogenic pulmonary edema following cardiopulmonary bypass associated with an antigranulocyte antibody. Anesthesiology. 1986;64:106-11.

25. Marczin N, Ryan US, Catravas JD. Effects of oxidant stress on endothelium-derived relaxing factor-induced and nitrovasodilator-induced cGMP accumulation in vascular cells in culture. Circ Res. 1992;70:326-40. 